\title{
Further Development of Process Maps for TRIP Matrix Composites during Powder Forging
}

\author{
Markus Kirschner ${ }^{1, a^{*}}$, Sergey Guk ${ }^{1, b}$, \\ Prof. Rudolf Kawalla ${ }^{1, c}$ and Prof. Ulrich Prahl ${ }^{1, d}$
}

\author{
${ }^{1}$ Bernhard-con-Cotta Str. 4, 09599 Freiberg, Deutschland \\ akirschner.markus@imf.tu-freiberg.de, bsergey.guk@imf.tu-freiberg.de, \\ crudolf.kawalla@imf.tu-freiberg.de, dulrich.prahl@imf.tu-freiberg.de
}

\begin{abstract}
Keywords: Process maps, powder forging, MMC, TRIP, particle reinforced steel, flow curves
\end{abstract}
\begin{abstract}
Process maps according to Parasad et al. are already widely used to make statements about the formability of materials and their forming energy. However, these process maps only apply to conventional incompressible materials. At the TU Bergakademie Freiberg, these process maps have already been extended for particle-reinforced incompressible solid materials with a homogeneous particle distribution. The next step is to adapt the model for compressible particle-reinforced matertials so that they can also be used in powder metallurgy. The problem here is that the volume decreases as a result of compaction during powder forming. In powder metallurgy, however, compaction plays an important role. On the one hand, the compaction of the components leads to an increase in the material properties. On the other hand, pores pose a high risk of fractures and cracking. For this reason, it is the aim of this paper to make the existing process maps for incompressible materials usable for compressible materials by corresponding adaptations of the models prevailing in powder metallurgy. Furthermore, the effects of a homogeneous particle distribution and a graded particle distribution within the TRIP matrix composites on the process maps will be investigated.

For this reason, process maps are produced in the temperature ranges between $700-1050{ }^{\circ} \mathrm{C}$, with forming speeds of $0.001-100 \mathrm{~s}^{-1}$ and residual porosity of $10-30 \%$. For this purpose, specimens with corresponding residual porosity and homogeneously distributed $\mathrm{ZrO}_{2} 5$ vol.\%, 10 vol.\%, $15 \mathrm{vol} . \%$ and $20 \mathrm{vol} . \%$ as well as a graded layer structure of corresponding $\mathrm{ZrO}_{2}$ proportions are prepared. With the aid of these specimens, flow curves are determined and adjusted at appropriate temperatures and forming speeds during compression tests. The energy dissipation and an instability map are then modelled from these flow curves and a process map is derived.

It was found that with increasing $\mathrm{ZrO}_{2}$ content in the homogeneous and the graded structure, the areas that allow damage-free forming become smaller. The same applies with decreasing residual porosity. Nevertheless, the areas, which allow failure-free forming, are larger than the possible forming areas of solid components. However, the power dissipation efficiency of incompressible specimens is significantly lower than that of compressible specimen [1]. In addition, it was observed that with increasing $\mathrm{ZrO}_{2}$ content and decreasing residual porosity, the efficiency of the power dissipation in the formable areas decreases. It was also found that the distribution of the reinforcing particles has a significant influence on the flow curves and the associated process maps, then the graded specimen do not represent a superposition of the individual process maps of the homogeneous specimens.
\end{abstract}

\section{Introduction}

Particle reinforced Metal Matrix Composites (PRMMC) combine the properties of a ductile metal matrix and functional ceramic particles. Their application is advantageous due to a higher stiffness, improved strength with a marginal loss of ductility or a better wear resistance in comparison with the unreinforced metal [2-4]. Exceptional potential lies in the development of composites based on high energy absorbing TRIP/TWIP steels and transformable zirconia $\left(\mathrm{ZrO}_{2}\right)$ particles [5-8]. The MgOpartially stabilized zirconia (Mg-PSZ) reinforcement is supposed to increase the strength as well as the toughness of the composite, due to its ability to undergo a stress-induced phase transformation from the tetragonal to the monoclinic phase [9-11]. However, this mechanism only works up to a 
temperature of $600{ }^{\circ} \mathrm{C}[12,13]$. Furthermore, the metastable austenitic steel matrix provides a deformation-induced rise of both strength and ductility, due to the transformation induced plasticity (TRIP) effect. [14, 15]. This mechanism only works up to a temperature of $100{ }^{\circ} \mathrm{C}[12,16]$.

Since 1982, attempts have been made to describe the deformation energy using process maps. The beginnings for this can be traced back to Forst and Ashby [17]. The final calculation model that is used today was drawn up by Parasad et al. [18-23]. At the Institute for Metal Forming of the TU Bergakademie Freiberg process maps according to the model of Parasad et al. for incompressible components made of compact material composites from the TRIP-Matrix Composite with a homogeneous $\mathrm{ZrO}_{2}$ distribution have already been created and the influencing parameters have been examined in detail [1].

However, in order to produce process maps for powder metallurgical production processes that start from a porous initial state, important adaptations to the recognized process according to Prasad et al. must be made. Because this model only applies to compact materials [19, 24-26]. Since the same assumptions as for incompressible materials cannot be made for powder metallurgy components due to their residual porosity and the resulting compressibility, the model must be adapted to compressible materials [27].

For this an adjustment of the flow curve according to Nguyen is applied. According to this, the general equation (1) of the flow stress for incompressible materials is extended from a POISSON number to a density-dependent plastic POSSION number [27].

$$
k_{f}=\frac{F}{\frac{\pi d^{2}}{4}\left(1+\frac{\mu d}{3 h} \vartheta_{\rho}\right)}
$$

Here $F$ represents the forming force, $d$ the specimen diameter, $\mu$ the coefficient of friction, $h$ the specimen height and $\vartheta_{\rho}$ the density-dependent plastic POSSION number. The density-dependent plastic POSSION number in turn is as follows [27, 28].

$$
\vartheta_{\rho}=0,5 \cdot \rho_{R}^{c}
$$

$\rho_{R}$ is the relative density and $c$ a density-dependent function that determines the compressibility of a material. This function can be assumed according to Kuhn and Downey hot forming of steels with a value of $c=2$ [28]. This results in powder metallurgical steels:

$$
\vartheta_{\rho}=0,5 \cdot \rho_{R_{0}}^{2} \cdot e^{2 \varphi_{\rho}}
$$

Here $\rho_{R_{0}}$ is the relative density in the initial state and $\varphi_{\rho}$ represents the degree of compaction, which in turn is defined as [27]:

$$
\varphi_{\rho}=-\frac{1}{2} \cdot \ln \left[\rho_{R_{0}}^{2}-e^{2 \varphi_{h}}\left(\rho_{R_{0}}^{2}-1\right)\right]
$$

$\varphi_{h}$ represents the logarthmic deformation degree over the sample height. With this adaptation of the flow stress model to compressible materials, it is possible to enter corresponding data into the method implemented by Prasad et al. and to use them further [27].

Powder metallurgical materials cannot only be produced homogeneously, but also as gradient materials as Figure 1 shows. 
a)

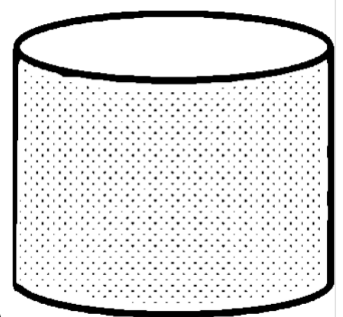

Figure 1: Types of specimens, a) homogenous distribution of $\mathrm{ZrO}_{2}$ b)

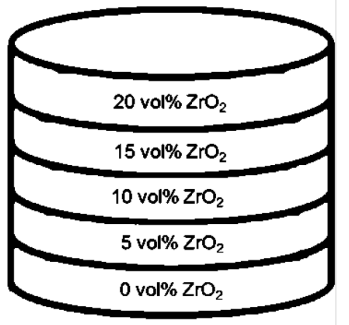

b) graded distribution of $\mathrm{ZrO}_{2}$

Here, too, some adjustments must be made to the model of porous material. These include an adjustment of the friction due to the different material compositions between the specimen foot and specimen head, the specimen diameter due to the different bulges of the individual layers due to the different compositions and the associated different stresses in the individual layers, as well as the different residual porosity in the individual layers. [29]. After corresponding investigations it could be determined that, the difference of the residual porosities of the individual layers only deviates by approx. $2-3 \%$ with increasing $\mathrm{ZrO}_{2}$ content. Therefore, this can be neglected in the adaptation of the model.

The other two adaptations of the model are directly related. Due to the different $\mathrm{ZrO}_{2}$ contents of the layers of the specimen and the associated different stresses of the individual layers, there is no normal bulging of the specimens, as is the case with a homogeneous material. The specimen foot with a layer of pure TRIP steel will first form and bulge than the specimen head. The friction also changes due to the increase in surface area of the sample foot. This results in an increase of $\mu$. If $\mu$ increases during upsetting, the yield stress increases during the forming process [29]. Thus, due to the $\mathrm{ZrO}_{2}$ content as well as the bulge, $\mu$ must be adapted to the sample head and sample foot. Therefore, the following adjustment of $\mu$ in the calculation of $k_{f}$ was made:

$$
\mu=\frac{2 h \cdot\left(\frac{4 \mathrm{~F}}{\mathrm{~d}^{2} \pi}-1\right)}{\frac{d-d_{0}}{2}}
$$

$F$ represents the applied stress $[30,31]$. Since the process maps were calculated with the maximum of $k_{f}$ and no complete deformation of the sample has occurred, the coefficient of friction at the sample head cannot be assumed to be constant with $\mu=1$ due to any changes in the layer. Therefore an adjustment of $\mu$ is only necessary at the sample foot. After these additional adaptations to the model of Parasad et al., the rest of the process maps can still be calculated according to the model of Parasad et al. [29].

The aim of the present paper is to make the existing process maps for incompressible components usable by corresponding adaptations of the models for compressible components as they predominate in powder metallurgy. This is of decisive for further processing and forming. In addition, the effects of grading within particle-reinforced TRIP matrix composites on process maps will be investigated.

\section{Material and Methods}

The investigated material is a composition of gas-atomized steel powder which was austenitic in structure $\left(\mathrm{d}_{10}=8 \mu \mathrm{m}, \mathrm{d}_{50}=20 \mu \mathrm{m}\right.$ and $\left.\mathrm{d}_{90}=127 \mu \mathrm{m}\right)$ and Mg-PSZ ceramic powder $\left(\mathrm{d}_{10}=10.6 \mu \mathrm{m}\right.$, $\mathrm{d}_{50}=17.8 \mu \mathrm{m}$ and $\left.\mathrm{d}_{90}=29.6 \mu \mathrm{m}\right)$. The chemical composition of both, the metastable high alloyed TRIP-steel (indicated as 16-7-6) and the $\mathrm{ZrO}_{2}$ ceramic are shown in Table 1. The ceramic particle content was set to 0 vol. $\%, 5$ vol. $\%, 10$ vol. $\%, 15$ vol. $\%, 20$ vol. $\%$ and a graded layer structure of these five contents as shown in Figure 1. The two powder components were mixed and cold precompressed into cylindrical form with a diameter of $\varnothing 10 \mathrm{~mm} \times 20 \mathrm{~mm}$ at a uniaxial pressure of $130 \mathrm{MPa}$. Finally these cylinders were sintered under Vakuum at $1100{ }^{\circ} \mathrm{C}$ for $60 \mathrm{~min}$. The heating and cooling rates were $10 \mathrm{~K} / \mathrm{min}$, respectively. 
Table 1: Nominal chemical composition of the TRIP steel powder and the Mg-PSZ powder

\begin{tabular}{|c|c|c|c|c|c|c|c|c|c|c|c|}
\hline TRIP steel & $\mathrm{Fe}$ & C & $\mathrm{Cr}$ & $\mathbf{N i}$ & Mn & Si & $\mathbf{N}$ & Al & $\mathbf{S}$ & Mo & $\mathbf{T i}$ \\
\hline [wt.\%] & bal. & 0.03 & 16.3 & 6.6 & 7.2 & 1.0 & 0.09 & 0.04 & $<0.01$ & $<0.01$ & $<0.01$ \\
\hline MgO-PSZ & $\mathrm{ZrO}_{2}$ & $\mathrm{HfO}_{2}$ & MgO & $\mathrm{SiO}_{2}$ & $\mathrm{Al}_{2} \mathrm{O}_{3}$ & $\mathrm{CaO}$ & $\mathrm{TiO}_{2}$ & $\mathrm{Y}_{2} \mathrm{O}_{3}$ & & & \\
\hline [wt.\%] & bal. & 1.85 & 3.25 & 0.10 & 1.58 & 0.06 & 0.13 & 0,13 & & & \\
\hline
\end{tabular}

The workability and flow behavior of the composite was investigated by uniaxial compression tests. The simulation of the powder forging process were carried out at a servo-hydraulic hot deformation simulator. Therefore, the specimens were putted into a breaker heated up all together in a furnace. The temperature range was from $700{ }^{\circ} \mathrm{C}$ to $1050{ }^{\circ} \mathrm{C}$. Afterwards, the breakers were putted into the hot deformation simulator at forming speeds of $0.001-100 \mathrm{~s}^{-1}$. In order to reduce friction, a graphite lubricant was used.

The following numerical analysis was carried out in MathLab. Therefore, flow curves were determined at appropriate temperatures and forming speeds. The energy dissipation and an instability map were modelled from these flow curves and a process map is derived. The grey areas of the maps corresponds instable deformation. The numbers at the isolines represent the efficiency of the dissipation process. One part of the energy used for the forming process is lost, for example, through heating. Therefore, it is no longer available for closing pores, dynamic recrystallisation, etc. The figures are therefore the values for the efficiency of the power dissipation under corresponding transformation conditions.

\section{Results}

For specimens with different $\mathrm{ZrO}_{2}$ contents and different residual porosities, powder forging was simulated in order to specify more precisely the material flow and to analyse the degree to that the composite material can be formed. Therefore, the temperature range $700-1050{ }^{\circ} \mathrm{C}$ was examined. Out of that data the following process maps can be calculated:
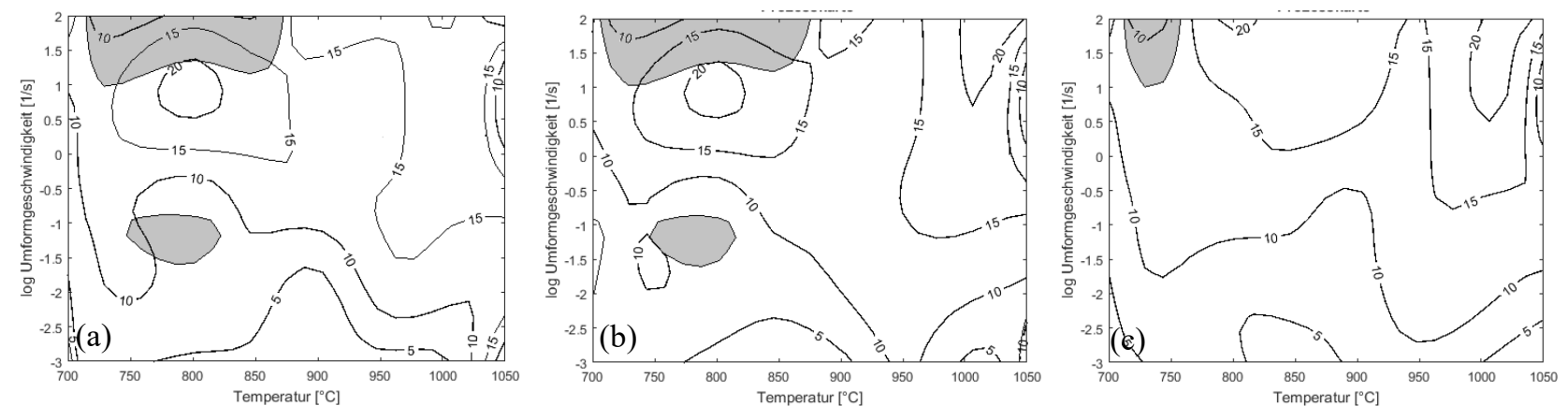

Figure 2: Process maps with 0 vol. $\% \mathrm{ZrO}_{2}$ and a residual porosity of $10 \%$ (a), $20 \%$ (b), and $30 \%$ (c)

Fore pure TRIP steel in Fig. 2 it can be observed that new the isolines appear and existing isolines shift strongly, starting from a residual porosity of $30 \%$ to a residual porosity of 10 . The amount of power dissipation is from $5 \%$ to $20 \%$. Furthermore, it can be seen that the only area that does not allow forming is between the forming speeds of $\log 2-\log 1 \mathrm{~s}^{-1}$ at all temperatures. In addition, component failure occurs at forming speeds of $\log 0,5-\log 0 \mathrm{~s}^{-1}$ and $\log -1-\log -1,5 \mathrm{~s}^{-1}$ within a temperature range of $750-800^{\circ} \mathrm{C}$ and $900-950{ }^{\circ} \mathrm{C}$. In addition, it can be observed that with residual porosity increase, the proportion of areas in which forming without failure is possible, increases. For this reason, the area in which cracks and internal stresses occur during production drops from $11.8 \%$ to $8.4 \%$ to $2.6 \%$. 

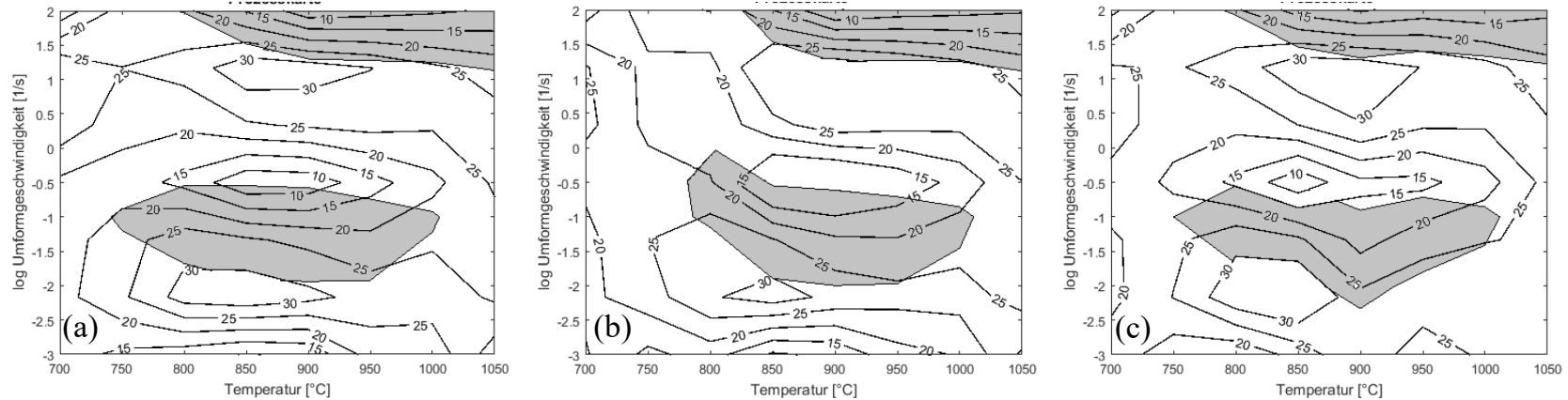

Figure 3: Process maps with 5 vol. $\% \mathrm{ZrO}_{2}$ and a residual porosity of $10 \%$ (a), $20 \%$ (b), and $30 \%$ (c)

With a $\mathrm{ZrO}_{2}$ content of $5 \%$ it can be seen in Fig. 3 that the isolines of energy dissipation narrow from a residual porosity of $10 \%$ to $30 \%$ and the peaks become clearer. However, the values of the isolines of the efficiency of the power dissipation are raising with the residual porosity. It can also be noticed that component failure occurs at high forming speeds independent of temperature. In addition, component failure occurs at forming speeds of $\log -0,5-\log -2 \mathrm{~s}^{-1}$ within a temperature range of $800-1000{ }^{\circ} \mathrm{C}$. The surface area in which cracks and internal stresses occur during production is around $21 \%$ for all three residual porosities.
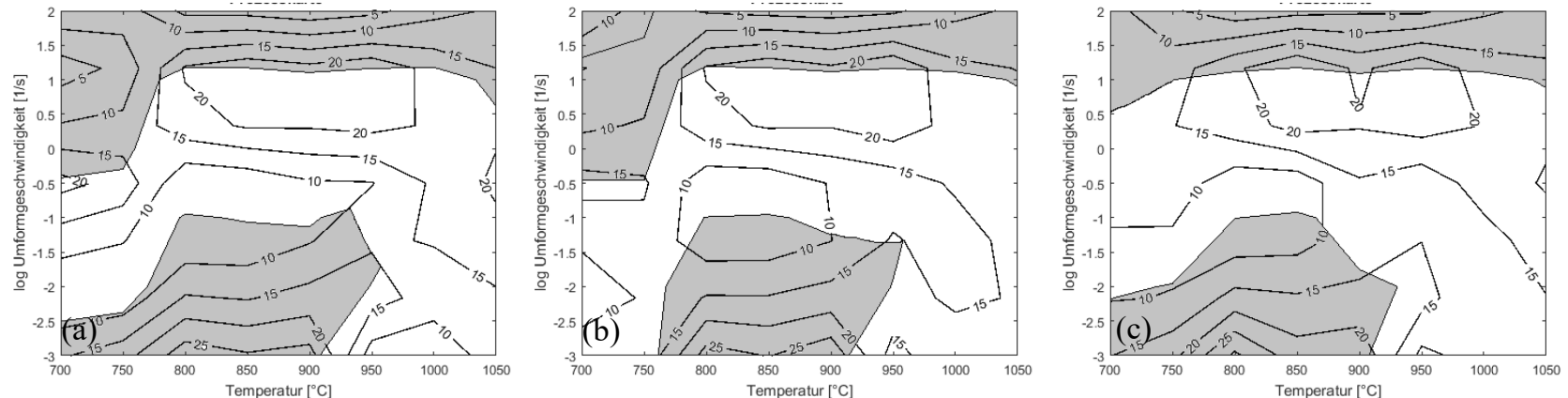

Figure 4: Process maps with 10 vol. $\% \mathrm{ZrO}_{2}$ and a residual porosity of $10 \%$ (a), $20 \%$ (b), and $30 \%$ (c)

At a $\mathrm{ZrO}_{2}$ content of $10 \%$ in Fig. 4, the isolines of energy dissipation do not pull together as with the specimens with $5 \% \mathrm{ZrO}_{2}$ and become clearer with increasing residual porosity, but the isolines become wider and enlarge their area. However, it is clear to see that the areas become larger with increasing efficiency of power dissipation. Furthermore, you can see that at high forming speeds of $\log 1 \mathrm{~s}^{-1}$ no forming without component failure is possible. The same applies in the temperature range between $700-950{ }^{\circ} \mathrm{C}$ and forming speeds of $0.001-0.1 \mathrm{~s}^{-1}$. Here, only a forming with component failure is possible. It can also be realized that as the residual porosity decreases, the proportion of areas in which forming is possible without failure decreases. The area in which cracks and internal stresses occur during production increases from $35.5 \%$ to $37.3 \%$ to $39.5 \%$.
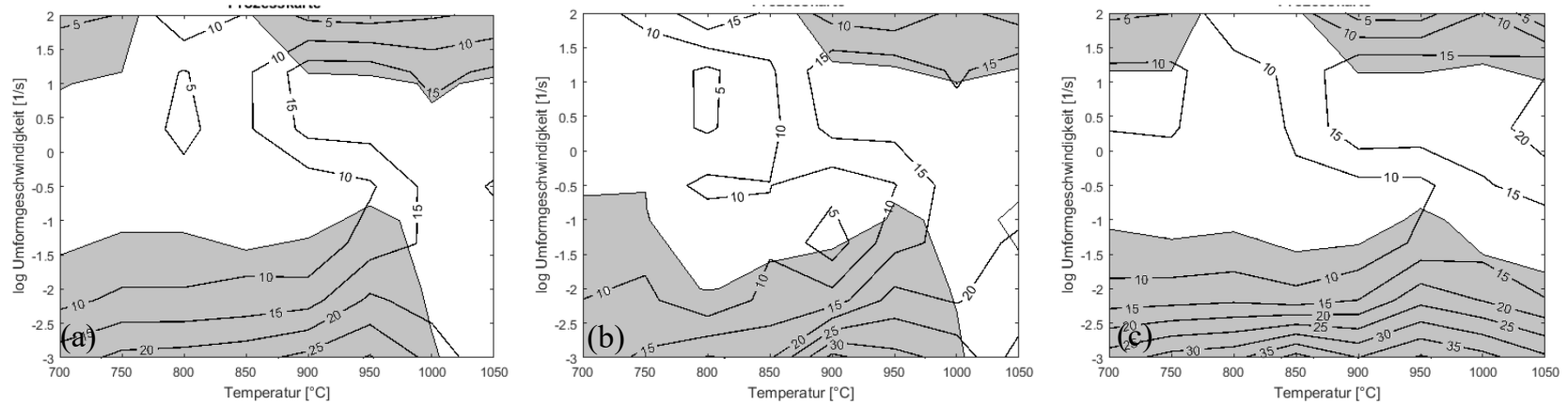

Figure 5: Process maps with 15 vol. $\% \mathrm{ZrO}_{2}$ and a residual porosity of $10 \%$ (a), $20 \%$ (b), and $30 \%$ (c)

With $15 \% \mathrm{ZrO}_{2}$ it can be seen that, starting from a residual porosity of $30 \%$ to a residual porosity of $10 \%$, new isolines appear and existing isolines shift strongly. In addition, the efficiency of the power dissipation increases rapidly from $20 \%$ to $35 \%$. It can also be observed that the areas into which 
deformation is damage-free are strongly shifted. The area in which component failure occurs changes from $40.3 \%$ to $42 \%$ to $44 \%$ with decreasing residual porosity, as with the specimens with $10 \%$ $\mathrm{ZrO}_{2}$. Only the range between $900-1050{ }^{\circ} \mathrm{C}$ at a forming speed of $\log 1-\log -1 \mathrm{~s}^{-1}$ is constant. As well as the range between $700-1000^{\circ} \mathrm{C}$ and a forming speed of $\log -1,5-\log -3 \mathrm{~s}^{-1}$.
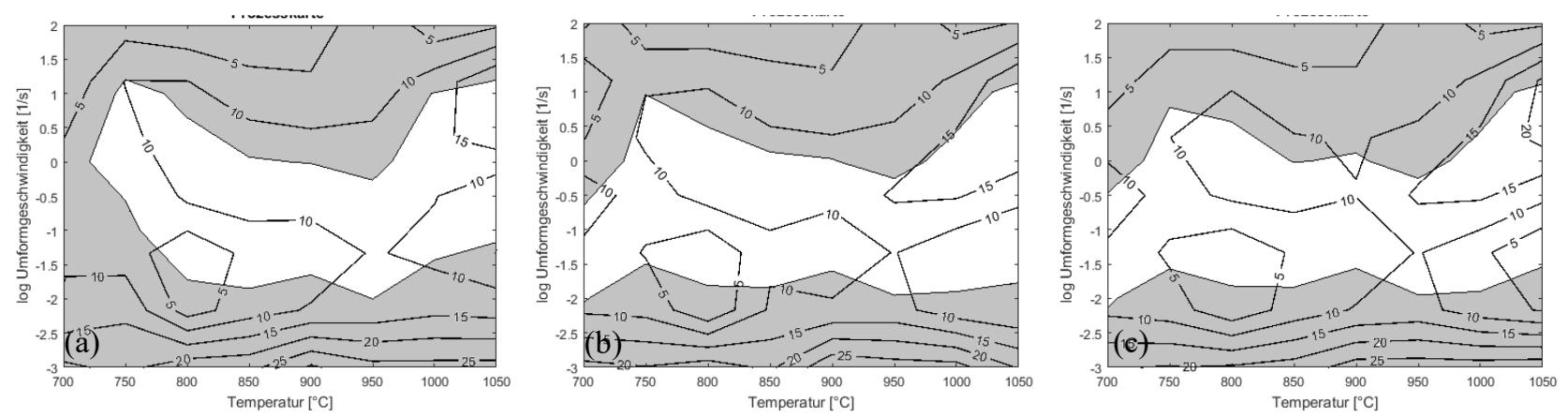

Figure 6: Process maps with 20 vol. $\% \mathrm{ZrO}_{2}$ and a residual porosity of $10 \%$ (a), $20 \%$ (b), and $30 \%$ (c)

With a $\mathrm{ZrO}_{2}$ content of $20 \%$ in Fig. 6 it can be observed that the isolines of energy dissipation hardly change. They remain almost identical to the other specimens. The small amount of power dissipation that changes, however, behaves as in the specimens with 5 vol.\% $\mathrm{ZrO} 2$. Furthermore, it can be seen that the only area that allows forming is between the forming speeds $\log -1,5-\log 0 \mathrm{~s}^{-1}$ at all temperatures. Except for a residual porosity of $10 \%$. Here the temperature window is between $750-$ $1050{ }^{\circ} \mathrm{C}$. In addition, with increasing residual porosity the proportion of areas in which forming without failure is possible increases. The area in which cracks and internal stresses occur during production drops from $58 \%$ to $55.8 \%$ to $53.4 \%$.

The area, which allows damage-free deformation, is nearly the same for all residual porosities in the specimens with 5 vol. $\% \mathrm{ZrO}_{2}$. This can be explained by the fact that at a $\mathrm{ZrO}_{2}$ content of $5 \mathrm{vol} . \%$ the particles do not strongly impede the matrix flow. Therefore, even with an increasing residual porosity, which requires a higher forming for compression and deformation, no difference to a low residual porosity can be determined.

With an increasing proportion of $\mathrm{ZrO}_{2}$, the formability decreases. The same applies to a decreasing proportion of residual porosity. This can be explained by the fact that the particles represent a barrier against the flow of the matrix. The hydrostatic stress field generated by the accumulation of particles in the matrix counteracts the material flow. On the one hand, higher forces are required to make the material flow. On the other hand, slight cracks develop during the forming process, as cracks are easily initiated at stress fields, which usually occur at the poles of the particles, when the material does not flow despite of increasing hydrostatic stresses [32]. The reason for the decreasing proportion of formable areas within the process maps between the different residual porosities can be explained by the residual porosities themselves. As the residual porosity decreases, the areas in which forming without component failure is possible also decreases. This is due to the fact that with a high proportion of residual porosity, the sample is first compressed even further. A specimen with only $10 \%$ residual porosity cannot be compacted as far by the material flow as a specimen with $30 \%$ residual porosity. Therefore, the area for forming is larger for these process maps.

For all $\mathrm{ZrO}_{2}$ contents, a high forming rate of $100-10 \mathrm{~s}^{-1}$ leads to temperature-independent cracks in the component. At high forming speeds of $10-100 \mathrm{~s}^{-1}$, the particles act as an obstacle to matrix flow, as the particles have no time to flow with the matrix. This leads to hydrostatic stress fields, which are generated by the particles in the matrix. These counteract the material flow and thus the crack-free forming process. At lower forming speeds, however, the material has enough time to flow and the particles float in the matrix. As a result, no or only very few and small hydrostatic stress fields are generated. As the matrix can flow uninhibited and the particles are only a small obstacle to the material flow during slow forming, there is no crack initiation due to the forming. 
With decreasing residual porosity, the efficiency of the power loss in the formable areas decreases. This can be explained by the fact that with a high residual porosity more energy is required to close the pores. Therefore, the loss of efficiency of the power loss is greater with increasing residual porosity.
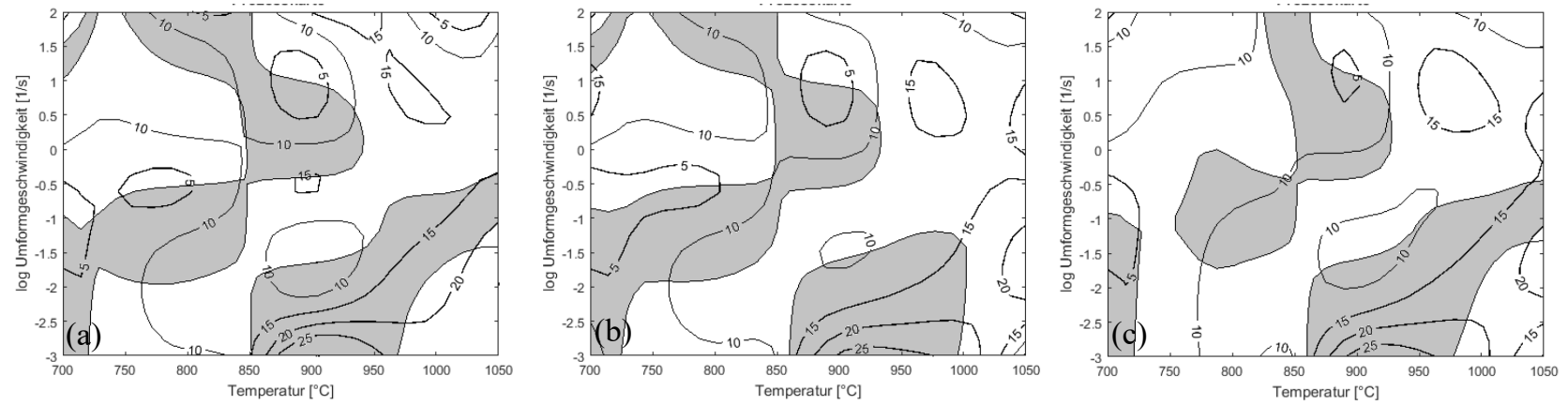

Figure 7: Process maps with graded $\mathrm{ZrO}_{2}$ layer structure and a residual porosity of $10 \%$ (a), $20 \%$ (b) and $30 \%$ (c)

With a graded layer structure, shown in Fig. 7, it can be noticed that the power loss, as with the previous specimens, ranges between $5 \%$ and $25 \%$. However, this is primarily between $5 \%$ and $10 \%$ and there are also fewer isolines than with the homogeneous specimens, which overall means that only a very small amount of the energy, which is applied for forming, is lost.

Furthermore, it can be seen that the range which allows forming is between the forming speeds $\log -0,5-\log 0,5 \mathrm{~s}^{-1}$ at all temperatures, with the exception of the temperature range between $800-920^{\circ} \mathrm{C}$. This is instable regardless of the forming speeds. With this value, in which forming without distortion is possible, the forming rate lies exactly between the values of the homogeneous specimens.

The surface area in which cracks and internal stresses occur during production is around $40 \%$ for all three residual porosities and lies exactly between the values of the homogeneous specimens with a $\mathrm{ZrO}_{2}$ content greater than 5 vol.\%.

In addition, it can be observed that the instable areas in which forming is not possible without failure of the component, cannot be compared with the areas of homogeneous particle distribution. However, similarities can be found. As in the upper areas on the left and right. In these areas no forming is possible for all specimens. The area in the middle of the process map for the graded components can only found for specimens with a $\mathrm{ZrO}_{2}$ content of 5 vol.\%. The same applies to the unstable forming area in the middle of the process map at the bottom. This is only found in specimens with a $\mathrm{ZrO}_{2}$ content of $15 \mathrm{vol} . \%$. The unstable area on the lower left is found on all process maps with a $\mathrm{ZrO}_{2}$ content of more than $5 \mathrm{vol} . \%$. Thus, it can be recognized that the process maps are not a superposition of the individual process maps in which the $\mathrm{ZrO}_{2}$ particles are homogeneously distributed, but form their own structure. However, there are similarities with the process maps of the homogeneous specimens.

These are then spread over all compositions as already described. All this can be explained above all by the different hydrostatic stress fields within and between the individual layers. As a result, the forming speeds and formable areas of the inhomogeneous specimens are similar to the homogeneous specimens and the parameters do not exceed the defined limits of the homogeneous specimens. However, these graded specimens form an independent forming system with their own hydrostatic stresses and flow conditions. 


\section{Conclusion}

In the present work, the hot formability of a 16-7-6 CrMnNi TRIP steel with different distributions of $\mathrm{ZrO}_{2}$ was examined in compression testing between $700-1050{ }^{\circ} \mathrm{C}$, with forming speeds of $0.001-100 \mathrm{~s}^{-1}$ and residual porosity of $10-30 \%$. Out of this, process maps were produced to find out to what extent the composite material can be formed or how large the material flow can be before cracking occurs. Some major conclusions can be drawn:

- Process maps of the graded specimens do not represent a superposition of the individual process maps of the homogeneous specimens, but form an independent system, although similarities to the process maps of the homogeneous specimens can be recognized.

- The area, which permits forming without damage, is the same for all residual porosity as for the specimens with 5 vol.\% $\mathrm{ZrO}_{2}$.

- The area, which permits forming, becomes smaller with decreasing residual porosity.

- The area, which allows a forming without damage, becomes smaller with increasing $\mathrm{ZrO}_{2}$ content in the matrix.

- For all $\mathrm{ZrO}_{2}$ contents, a high forming speed of $100-10 \mathrm{~s}^{-1}$ leads to cracks in the component independent of temperature.

- With increasing $\mathrm{ZrO}_{2}$ content as well as with decreasing residual porosity, the efficiency of the power loss in the formable areas decreases.

- The process maps have a close relationship with the forming rate, the $\mathrm{ZrO}_{2}$ content and the residual porosity. Ultimately, the desirable temperature and forming rate to work on 16-7-6 CrMnNi TRIP Matrix Composites is $950-1050{ }^{\circ} \mathrm{C}$ and between $0,3-10 \mathrm{~s}^{-1}$.

\section{Acknowledgements}

This work was financed by the German Research Foundation or Deutsche Forschungsgemeinschaft (DFG), and was created as part of the Collaborative Research Center TRIP-Matrix-Composites (SFB 799), subproject A6 I.

\section{References}

[1] S. Guk, D. Milisova, K. Pranke, KEM 2016, 684, 86-96. DOI: $10.4028 /$ www.scientific.net/KEM.684.86.

[2] N. Chawla, Y.-L. Shen, Adv. Eng. Mater. 2001, 3 (6), 357 - 370. DOI: 10.1002/15272648(200106)3:6<357:AID-ADEM357>3.3.CO;2-9.

[3] J. W. Kaczmar, K. Pietrzak, W. Włosiński, Journal of Materials Processing Technology 2000, 106 (1-3), 58 - 67. DOI: 10.1016/S0924-0136(00)00639-7.

[4] D. MIRACLE, Composites Science and Technology 2005, 65 (15-16), 2526-2540. DOI: 10.1016/j.compscitech.2005.05.027.

[5] H. Biermann, U. Martin, C. G. Aneziris, A. Kolbe, A. MÃ¹/4ller, W. SchÃărfl, M. Herrmann, Adv. Eng. Mater. 2009, 43, NA-NA. DOI: 10.1002/adem.200900210.

[6] A. Glage, C. Weigelt, J. Räthel, H. Biermann, International Journal of Fatigue 2014, 65, 9 - 17. DOI: 10.1016/j.jifatigue.2013.11.025.

[7] D. Ehinger, L. Krüger, U. Martin, C. Weigelt, C. G. Aneziris, International Journal of Solids and Structures 2015, 66, 207 - 217. DOI: 10.1016/j.ijsolstr.2015.02.052.

[8] C. Weigelt, E. Jahn, H. Berek, C. G. Aneziris, R. Eckner, L. Krüger, Adv. Eng. Mater. 2015, 17 (9), 1357 - 1364. DOI: 10.1002/adem.201400559.

[9] Y. Zhou, Y. Guo, D. Li, X. Duan, Trans. Nonferrous Met. Soc. China 2003 (13), 1086 - 1091.

[10] Y. Guo, Y. Zhou, D. Li, X. Duan, T. Lei, J. Mater. Sci. Technol. 2003 (19), 137 - 140. 
[11] C. Weigelt, C. G. Aneziris, D. Ehinger, R. Eckner, L. Krüger, C. Ullrich, D. Rafaja, Journal of Composite Materials 2015, 49 (28), 3567 - 3579. DOI: 10.1177/0021998314567698.

[12] S. Decker, Entwicklung der Mikrostruktur und der mechanischen Eigenschaften eines Mg-PSZpartikelverstärkten TRIP-Matrix-Composits während Spark Plasma Sintering, Dissertation, Logos Verlag Berlin GmbH.

[13] A. Reckziegel, Friatec $A G 2015$ (2), 1 - 10.

[14] V. F. Zackay, E. R. Parker, D. Fahr, R. Busch, Trans. Am. Soc. 1967 (60), 252 - 259.

[15] I. Tamura, Metal Science 2013, 16 (5), 245 - 253. DOI: 10.1179/030634582790427316.

[16] A. Weidner, Stahl-Online, 2016, 16 - 19.

[17] H. J. Frost, M. F. Ashby, Deformation-mechanism maps: The plasticity and creep of metals and ceramics, 1st ed., Pergamon Press, Oxford, New York, Toronto, Sydney, Paris, Frankfurt Main i.e. Kronberg-Taunus 1982.

[18] R. Raj, MTA 1981, 12 (6), 1089 - 1097. DOI: 10.1007/BF02643490.

[19] Y. V. R. K. Prasad, H. L. Gegel, S. M. Doraivelu, J. C. Malas, J. T. Morgan, K. A. Lark, D. R. Barker, Metall. Trans. 1883 (15).

[20] S. Venugopal, S. L. Mannan, Y.V.R.K. Prasad, Materials Letters 1993, 17 (6), 388 - 392. DOI: 10.1016/0167-577X(93)90132-H.

[21] Y. V. R. K. Prasad, K. P. Rao, S. Sasidhara, Hot working guide: A compendium of processing maps, ASM International, Materials Park, OH 2015.

[22] Z. Huang, Z. Lu, S. Jiang, K. Zhang, J. Mater. Res. 2016, 31 (19), $2964-2976$. DOI: $10.1557 / \mathrm{jmr} .2016 .315$.

[23] Y. V. R. K. Prasad, T. Seshacharyulu, International Materials Reviews 2013, 43 (6), 243 - 258. DOI: 10.1179/imr.1998.43.6.243.

[24] Z. Chen, P. Nash, steel research int. 2018, 89 (3), 1700321. DOI: 10.1002/srin.201700321.

[25] Y. H. Duan, J. of Materi Eng and Perform 2013, 22 (10), 3049 - 3054. DOI: 10.1007/s11665013-0604-1.

[26] H. Wu, S. P. Wen, H. Huang, K. Y. Gao, X. L. Wu, W. Wang, Z. R. Nie, Journal of Alloys and Compounds 2016, 685, 869 - 880. DOI: 10.1016/j.jallcom.2016.06.254.

[27] Ngoc Nguyen, Einfluss von Verfahrensparamtern beim Pulverschmieden auf die Eigenschaften der gefertigten Werkstücke, Dissertation, TU Bergakademie Freiberg 1958.

[28] H. A. Kuhn, C. L. Downey, International Journal of Powder Metallurgy 1971, 15 - 25.

[29] Sven Raßbach, Grundlegende Untersuchungen zum Umformverhalten von Gradientenwerkstoffen unter Anwendung von Druckumformverfahren, Dissertation, TU Bergakademie Freiberg 2002.

[30] R. Dalheimer, K. Dieterle, K. Gieselberg, K. Lange, Lehrbuch der Umformtechnik, SpringerVerlag Berlin Heidelberg 1974.

[31] K. Lange, Massivumformung, 2nd ed., Umformtechnik, Handbuch für Industrie und Wissenschaft / Kurt Lange Hrsg. ; Bd. 2, Springer, Berlin 1988.

[32] S. Martin, S. Richter, S. Decker, U. Martin, L. Krüger, D. Rafaja, Steel Research 2011 (9), $1133-1140$. 